\title{
円錐平板型回転粘度計によるCasson流体ならびに Herschel-Bulkley流体の流動解析*
}

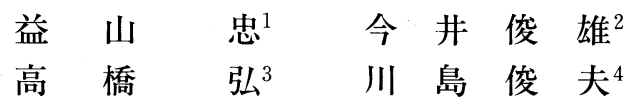

[UDC 621.6.01]

\section{Cone-and-Plate Viscometry of Casson Fluids and Herschel-Bulkley Fluids}

by Tadashi MASUYAMA ${ }^{1}$, Toshio IMAI ${ }^{2}$, Hiroshi TAKAHASHI ${ }^{1}$ and Toshio KAWASHIMA ${ }^{3}$

1. Faculty of Engineering, Tohoku University, Aoba-ku, Sendai 980

2. Kawasaki Steel Co.

3. Hachinohe Institute of Technology

Cone-and-plate viscometers are suitable and popular devices for measuring non-Newtonian fluid flow characteristics because the shear rate of fluids in the gap between the cone and the plate is constant and they are easy to operate and commercially available. In this paper, a theoritical analysis of the cone-and-plate viscometer for a Casson model fluid and a Herschel-Bulkley model fluid is presented.

Since the theoritical equations derived are complicated, especially for Herschel-Bulkley model fluid, the first and second approximate expressions of the equations are derived. It is found through the comparison between the theoritically calculated values and the approximates that the first approximate expression is unsuitable for the calculation in the case that the included angle between the cone and the plate is over $2^{\circ}$ to keep the relative error between the theoritical values and the approximate ones under $1 \%$.

Moreover, it is confirmed that the second approximate expression is applicable to the calculation in the case that the included angle is up to $4^{\circ}$ under the condition in which the relative error is less than $1 \%$.

KEY WORDS: Cone-and-Plate Viscometry, Non-Newtonian Fluid, Casson Fluid, Herschel-Bulkley Fluid

\section{1. は じめに}

円錐平板型回転粘度計においては流体のずり速度が一定となる ため, 非ニュートン流体の流動特性ならびにその物理定数の測定

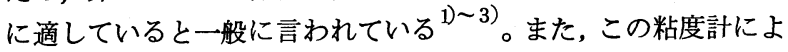
る流体の流動特性の決定方法ならびに擬塑性流体（以下，P流体 と記す) およびBingham 流体 (以下, B 流体と記す) の流動解析 の基礎式については既に報告がなされている ${ }^{4)}$ 。しかしながら, 分 散系スラリーの流動特性を良く説明しうるCasson流体（以下，C 流体と記す) モデルおよび Herschel-Bulkley 流体 (以下, $\mathrm{H} ・ \mathrm{~B}$ 流体と記す）モデルの流動解析の基礎式，とりわけ基礎式の近似 式に対する円錐と平板との挟角の影響については, 報告がなされ ていない。それゆえ, 本研究は, 円錐平板回転粘度計によるC 流体 ならびに $\mathrm{H} \cdot \mathrm{B}$ 流体の物理定数の測定に資するため, これら流体 の流動解析の基礎式を提示することを目的とするとともにその近 似式の精度と円錐・平板間の挟角との関係を明らかにしようとす るものである。なお，円錐平板回転粘度計には，平板を固定し円 錐を回転させる型式と円錐を固定し平板を回転させる型式の 2 型 式があるが，本研究においては，心出しが比較的容易であり，か つ,よく用いられている前者の型式を取り上げて論ずることにす る。

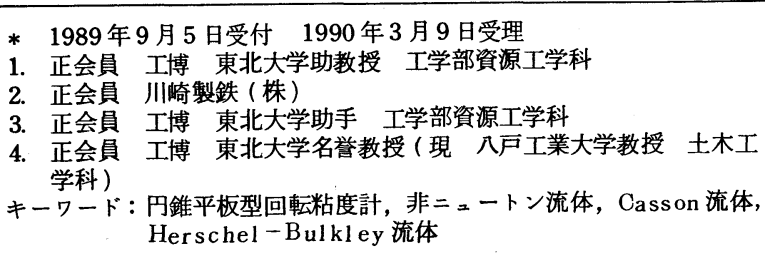

\section{2. 流動解析の基礎式}

円錐平板型回転粘度計による C 流体ならびに $\mathrm{H} ・ \mathrm{~B}$ 流体の流動 解析の基礎式を誘道する際に必要な, 円錐の角速度 $\Omega$ と流動方程 式との関係ならびに円錐に働くトルクMについては, 図1に示す

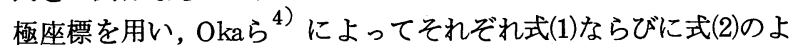
うに求められている。

$$
\begin{aligned}
& \Omega=\int_{0}^{\alpha} \sec \Psi f(\tau) d \Psi=\int_{0}^{\alpha} \sec \Psi f\left(K \sec ^{2} \Psi\right) d \Psi \quad \cdots \cdots \cdots \\
& M=\int_{0}^{a} \int_{0}^{2 \pi} r \cos \alpha(\tau)_{\Psi=\alpha} r \cdot d r \cdot d \phi \\
& =\int_{0}^{a} \int_{0}^{2 \pi} \frac{K r^{2}}{\cos \alpha} d r \cdot d \phi=\frac{2 \pi a^{3} K}{3 \cos \alpha}
\end{aligned}
$$

ここに，Kは運動方程式の積分定数である。

なお，上式の誘導にあたり，次の仮定が設けられている。

(i ) 流体は非時間依存性非ニュートン流体である。

(ii ) 流体は非圧縮性流体である。

(iii ) 流体の運動は定常層流流れである。

(iv)流体に働く体積力は無視しうる。

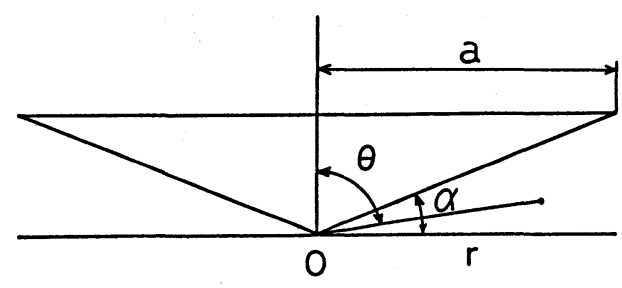

Fig. 1 Schematic illustration of spherical coordinates in cone and plate viscometer. 
（v）流体の運動は回転軸に対して対称性を有する。

(vi) 流体の微小部分は軸に垂直な水平面上にて円運動をする。 (vii) 流体と円錐ならびに平板との間には，すべりがない。

(viii)末端効果は無視しうる。

\section{2・1 Casson 流体の流動解析基礎式}

Casson 流体の流動曲線は，次のように与えられる。

$\tau>\tau_{y}: \dot{r}=f(\tau)=\left(\sqrt{\tau}-\sqrt{\tau_{y}}\right)^{2} / \mu_{\mathrm{C}}$

$\tau \leqq \tau_{y}: \dot{r}=f(\tau)=0$

式(3)を式(1)に代入し積分を行えば，トルクMの大きさにより，次 なる関係を得る。

a) $M \leqq 2 \pi a^{3} \tau_{y} \cos \alpha / 3$ の場合

$$
\Omega=0
$$

b) $2 \pi a^{3} \tau_{y} \cos \alpha / 3<M \leqq 2 \pi a^{3} \tau_{y} \sec \alpha / 3$ の場合

$$
\begin{aligned}
& \Omega=\int_{\Psi_{y}}^{\alpha} \sec \Psi \frac{1}{\mu_{\mathrm{C}}}\left(\sqrt{K \sec ^{2} \Psi}-\sqrt{\tau_{y}}\right)^{2} d \Psi \\
& =\frac{K}{4 \mu_{\mathrm{C}}}\left\{\frac{2 \sin \alpha}{1-\sin ^{2} \alpha}-\frac{2 \sin \Psi_{y}}{1-\sin ^{2} \Psi_{y}}+\log \left(\frac{1+\sin \alpha}{1-\sin \alpha} \cdot \frac{1-\sin \Psi_{y}}{1+\sin \Psi_{y}}\right)\right\} \\
& -\frac{2 \sqrt{\tau_{y}} \sqrt{K}}{\mu_{\mathrm{C}}}\left(\tan \alpha-\tan \Psi_{y}\right)+\frac{\tau_{y}}{2 \mu_{\mathrm{C}}} \log \left(\frac{1+\sin \alpha}{1-\sin \alpha} \cdot \frac{1-\sin \Psi_{y}}{1+\sin \Psi_{y}}\right)
\end{aligned}
$$

ただし, $\Psi_{y}$ は次の関係を満足する值である。

$$
\tau_{y}=K \sec ^{2} \Psi_{y}
$$

なお，式(5)の第 1 次近似ならびに第 2 次近似は，それぞれ次のよ うに表される。

$$
\begin{aligned}
\Omega= & \frac{K}{\mu_{\mathrm{C}}}\left(\alpha-\Psi_{y}\right)\left\{1-\sqrt{\frac{\tau_{y}}{K}}\right\}^{2} \\
\Omega= & \frac{K}{\mu_{\mathrm{C}}}\left(\alpha\left(1+\frac{\alpha^{2}}{2}\right)-\Psi_{y}\left(1+\frac{\Psi_{y}{ }^{2}}{2}\right)\right. \\
& -2 \sqrt{\frac{\tau_{y}}{K}}\left\{\alpha\left(1+\frac{\alpha^{2}}{3}\right)-\Psi_{y}\left(1+\frac{\Psi_{y}{ }^{2}}{3}\right)\right\} \\
& \left.+\frac{\tau_{y}}{K}\left\{\alpha\left(1+\frac{\alpha^{2}}{6}\right)-\Psi_{y}\left(1+\frac{\Psi_{y}}{6}\right)\right\}\right\}
\end{aligned}
$$

c) $M>2 \pi a^{3} \tau_{y} \sec \alpha / 3$ の場合

$$
\begin{aligned}
\Omega & =\int_{0}^{\alpha} \sec \Psi \frac{1}{\mu_{\mathrm{C}}}\left(\sqrt{K \sec ^{2} \Psi}-\sqrt{\tau_{y}}\right)^{2} d \Psi \\
& =\frac{K}{4 \mu_{\mathrm{C}}}\left\{\frac{2 \sin \alpha}{1-\sin ^{2} \alpha}+\log \left(\frac{1+\sin \alpha}{1-\sin \alpha}\right)\right\} \\
& -\frac{2 \sqrt{\tau_{y}} \sqrt{K}}{\mu_{\mathrm{C}}} \tan \alpha+\frac{\tau_{y}}{2 \mu_{\mathrm{C}}} \log \left(\frac{1+\sin \alpha}{1-\sin \alpha}\right)
\end{aligned}
$$

なお, 式(9)の第 1 次近似ならびに第 2 次近似は，それぞれ次のよ うに表される。

$$
\begin{aligned}
& \Omega=\frac{K}{\mu_{\mathrm{C}}} \alpha\left\{1-\sqrt{\frac{\tau_{y}}{K}}\right\}^{2} \\
& \Omega=\frac{K}{\mu_{\mathrm{C}}} \alpha\left\{1+\frac{\alpha^{2}}{2}-2\left(1+\frac{\alpha^{2}}{3}\right) \sqrt{\frac{\tau_{y}}{K}}+\left(1+\frac{\alpha^{2}}{6}\right) \frac{\tau_{y}}{K}\right\} \cdots \cdots(11)
\end{aligned}
$$

ただし，Kは式(2)より算出する。

2・2 Herschel-Bulkley 流体の流動解析基礎式

Hersche1-Bulkley 流体の流動曲線は, 次のように与えられる。

$\left.\tau>\tau_{y}: \dot{r}=f(\tau)=\left(\tau-\tau_{y}\right)^{n} / \mu_{\mathrm{HB}}{ }^{n}\right\}$

(12)

$\tau \leqq \tau_{y}: \dot{r}=f(\tau)=0$

式(12を式(1)に代入し積分を行えば，トルクMの大きさにより，次 なる関係を得る。

a) $M \leqq 2 \pi a^{3} \tau_{y} \cos \alpha / 3$ の場合

$\Omega=0$

b) $2 \pi a^{3} \tau_{y} \cos \alpha / 3<M \leqq 2 \pi a^{3} \tau_{y} \sec \alpha / 3$ の場合

$$
\begin{aligned}
\Omega & =\int_{\Psi_{y}}^{\alpha} \frac{\sec \Psi}{\mu_{\mathrm{HB}}{ }^{n}}\left\{K \sec ^{2} \Psi-\tau_{y}\right\}^{n} d \Psi \\
& =\left(\frac{K}{\mu_{\mathrm{HB}}}\right)^{n} \int_{\Psi_{y}}^{\alpha} \sec ^{2 n+1} \Psi\left\{1-\frac{\tau_{y} \cos ^{2} \Psi}{K}\right\}^{n} d \Psi \\
& =\left(\frac{K}{\mu_{\mathrm{HB}}}\right)^{n} \int_{\Psi_{y}}^{\alpha}\left(1+\sum_{J=1}^{\infty} \frac{E_{J} \Psi^{2 J}}{(2 \mathrm{~J}) !}\right)^{2 n+1} \\
& \left\{1-\frac{\tau_{y}}{K}\left(\sum_{i=0}^{\infty}(-1)^{i} \frac{\Psi^{2 i}}{(2 i) !}\right)^{2}\right\}^{n} d \Psi
\end{aligned}
$$

ただし， $\Psi_{y}$ は式(6)を満足する値であり, $E_{J}$ は Eulerの数 ${ }^{2}{ }^{25)}$ であ る。また, $n$ が自然数の場合には, 式(14)の定積分は初等関数によ って次のように表される。

$$
\begin{aligned}
& \Omega=\left(\frac{K}{\mu_{\mathrm{HB}}}\right)^{n} \int_{\Psi_{y}}^{\alpha} \sum_{r=0}^{n}(-1)^{r}{ }_{n} C_{r}\left(\frac{\tau_{y}}{K}\right)^{r} \sec ^{2(n-r)+1} \Psi d \Psi \\
& =\left(\frac{K}{\mu_{\mathrm{HB}}}\right)^{n} \sum_{r=0}^{n}\left[(-1)^{r}{ }_{n} C_{r}\left(\frac{\tau_{y}}{K}\right)^{r} \frac{(2(n-r-1)) ! !}{(2(n-r)) ! !}\right. \\
& \times\left\{\frac{\sin \alpha}{\cos ^{2(n-r)} \alpha} \sum_{J=0}^{n-r-1}\left[\frac{(2(n-r)-2 J-2) ! !}{(2(n-r)-2 J-1) ! !} \cos ^{2 J} \alpha\right]\right. \\
& -\frac{\sin \Psi_{y}}{\cos ^{2(n-r)} \Psi_{y}} \sum_{J=0}^{n-r-1}\left[\frac{(2(n-r)-2 J-2) ! !}{(2(n-r)-2 J-1) ! !} \cos ^{2 J} \Psi_{y}\right] \\
& \left.\left.+\frac{1}{2} \log \left(\frac{1+\sin \alpha}{1-\sin \alpha} \cdot \frac{1-\sin \Psi_{y}}{1+\sin \Psi_{y}}\right)\right\}\right]
\end{aligned}
$$

なお，式(14)の第 1 次近似ならびに第 2 次近似は，それぞれ次のよ うに表される。

$$
\begin{aligned}
\Omega & \left.=\left(\frac{K}{\mu_{\mathrm{HB}}}\right)^{n} \alpha\left(1-\frac{\Psi_{y}}{\alpha}\right)\left(1-\frac{\tau_{y}}{K}\right)^{n} \ldots \ldots \ldots \ldots \ldots \ldots \ldots . . . . . . . . . . . .16\right) \\
\Omega & =\left(\frac{K}{\mu_{\mathrm{HB}}}\right)^{n} \alpha\left\{\left\{\left(1+\frac{2 n+1}{6} \alpha^{2}\right)-\frac{\Psi_{y}}{\alpha}\left(1+\frac{2 n+1}{6} \Psi_{y}{ }^{2}\right)\right\}\right. \\
& \left.\times\left(1-\frac{\tau_{y}}{K}\right)^{n}+\frac{n \alpha^{2}\left(1-\left(\Psi_{y} / \alpha\right)^{3}\right)}{3} \frac{\tau_{y}}{K}\left(1-\frac{\tau_{y}}{K}\right)^{n-1}\right] \ldots \ldots .(17)
\end{aligned}
$$

c) $M>2 \pi a^{3} \tau_{y} \sec \alpha / 3$ の場合

$$
\begin{aligned}
\Omega & =\int_{0}^{\alpha} \frac{\sec \Psi}{\mu_{\mathrm{HB}}{ }^{n}}\left(K \sec ^{2} \Psi-\tau_{y}\right)^{n} d \Psi \\
& =\left(\frac{K}{\mu_{\mathrm{HB}}}\right)^{n} \int_{0}^{\alpha}\left(1+\sum_{J=1}^{\infty} \frac{E_{J} \Psi^{2 J}}{(2 J) !}\right)^{2 n+1} \\
& \left\{1-\frac{\tau_{y}}{K}\left(\sum_{i=0}^{\infty}(-1)^{i} \frac{\Psi^{2 i}}{(2 i) !}\right)^{2}\right\}^{n} d \Psi
\end{aligned}
$$

また, $n$ が自然数の場合には, 式(18)の定積分は初等関数によって 次のように表される。

$$
\begin{aligned}
& \Omega=\left(\frac{K}{\mu_{\mathrm{HB}}}\right)^{n} \sum_{r=0}^{n}\left[(-1)^{r}{ }_{n} C_{r}\left(\frac{\tau_{y}}{K}\right)^{r} \frac{(2(n-r-1)) ! !}{(2(n-r)) ! !}\right. \\
& \times\left\{\frac{\sin \alpha}{\cos ^{2(n-r)} \alpha} \sum_{J=0}^{n-r-1}\left[\frac{(2(n-r)-2 J-2) ! !}{(2(n-r)-2 J-1) ! !} \cos ^{2 J} \alpha\right]\right. \\
& \left.\left.+\frac{1}{2} \log \frac{(1+\sin \alpha)}{(1-\sin \alpha)}\right\}\right]
\end{aligned}
$$

なお，式(18)第 1 次近似ならびに第 2 次近似は，それぞれ次のよ うに表される。

$$
\begin{aligned}
& \Omega=\left(\frac{K}{\mu_{\mathrm{HB}}}\right)^{n} \alpha\left(1-\frac{\tau_{y}}{K}\right)^{n} \\
& \Omega=\left(\frac{K}{\mu_{\mathrm{HB}}}\right)^{n} \alpha\left\{\left(1+\frac{2 n+1}{6} \alpha^{2}\right)\left(1-\frac{\tau_{y}}{K}\right)^{n}\right. \\
& \left.+\frac{n \alpha^{2}}{3} \frac{\tau_{y}}{K}\left(1-\frac{\tau_{y}}{K}\right)^{n-1}\right\}
\end{aligned}
$$

以上，円錐回転式の場合について述べたが，平板回転式の場合 にも同様な結果が得られる。なお, 下記の点を考慮すれば, 型式 a) $E_{J}=\frac{(2 J) ! 2^{2 J+2}}{\pi^{2 J+1}} \sum_{r=0}^{\infty} \frac{(-1)^{r}}{(2 r+1)^{2 J+1}}$ 
的に上述の式をそのまま利用できる。すなわち, 平板回転式の場 合には, 式(2)における被積分関数は, $r^{2}(\tau) \psi_{=0}$ であることから, 平板に働くモーメント $M^{\prime}$ は $2 \pi a^{3} K / 3$ となる。従って, 型式的に $M^{\prime}=M \cos \alpha$ として取り扱えば，上述の式はそのまま利用できる。

\section{3. 解析値と近似値との比較検討}

円錐平板型回転粘度計による C 流体ならびに $\mathrm{H} ・ \mathrm{~B}$ 流体の流動 解析の基礎式ならびにそれらの近似式を 2 章において示したが, 同章において示したように $\mathrm{H} \cdot \mathrm{B}$ 流体の場合にはレオロジー定数 $n$ の值が自然数でない限り, 基礎式は切等関数で表しえない。そ れゆえ, 本章ではレオロジー定数 $n$ の値が自然数の場合について 基礎式による値と近似式による値とを比較し, 近似式の精度を評 価することにする。また，本章では, 流動解析の主なる状態であ る回転粘度計内の流体が完全に流動している場合についてこれら の値の比較検討を行う。すなわち, $2 \cdot 3$ 節ならびに $2 \cdot 4$ 節におけ る c)の場合について比較検討を行うことにする。なお, 比較の際 には，基礎式ならびに近似式による計算値を解析値 $T H$ ならびに 近似值 $A P$ と記し，次式に示す相対誤差を用いることにする。

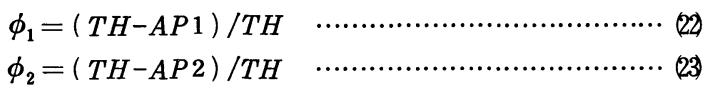

ここに, $T H, A P 1$ ならびに $A P 2$ は解析値, 第 1 次近似值ならび に第 2 次近似值をそれぞれ表す。

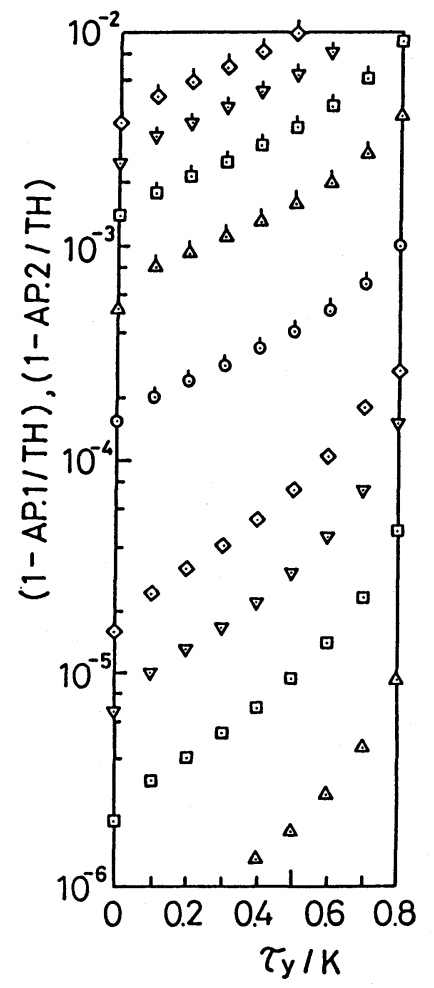

Fig. $2 T H$ : theoretical value;

$A P 1$ : first approximation value;

$A P 2$ : second approximation value

Dependence of $\phi_{1}(=(1-A P 1 / T H))$ and $\phi_{2}(=(1-A P 2 / T H))$ on $\tau_{y} / K$ for various values of angle $\alpha$ for

\begin{tabular}{|c|c|c|c|c|c|}
\hline$a^{\circ}$ & 1 & 2 & 3 & 4 & 5 \\
\hline irst & $\varnothing$ & $\Delta$ & 向 & 它 & 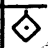 \\
\hline Second & $\odot$ & $\Delta$ & Q & $\nabla$ & $\odot$ \\
\hline
\end{tabular}
Casson model fluids.

Table 1 Symbols in figures.

図2 は, $\mathrm{C}$ 流体の $\phi_{1}$ および $\phi_{2}$ と $\tau_{y} / K$ との関係を挟角 $\alpha$ を次 ラメータとして図示したものである。なお, 図中の記号は表 1 に 示す記号と対応している。同図に示される範囲においては，第 1 次近似で相対誤差を $1 \%$ 以内に押さえるとするならば，挟角 $\alpha$ を 3 度以下にする必要があり, また, 相対誤差を $0.1 \%$ 以内にするた めには， $\alpha$ は 1 度以内にしなければならない。一方，第 2 次近似 を使用すれば， $\alpha$ が 5 度であっても相対誤差は $0.1 \%$ 以内である ことが分かる。

図了は，降伏值が零である $\mathrm{H} \cdot \mathrm{B}$ 流体すなわち, $\mathrm{H} \cdot \mathrm{B}$ 流体の特 別な場合の流体と考えられる $\mathrm{P}$ 流体について $\phi_{1}$ および $\phi_{2}$ とレオ ロジー定数 $n$ との関係を挟角 $\alpha$ をパラメータとして図示したもの である。同図に示されるように, この場合にも図 2 に示したC 流 体の場合と同様のことが言える。

図 4 は, レオロジー定数 $n$ の值が 1 である $\mathrm{H} \cdot \mathrm{B}$ 流体, すなわち, $\mathrm{H} \cdot \mathrm{B}$ 流体の特別な場合の流体と考光られる B 流体について, 図 2 に示した C 流体と同様な関係として図示したものである。同図 に示される範囲においては, 相対誤差を $1 \%$ 以内に押さえるには, 第 1 次近似では挟角 $\alpha$ を 4 度以下にする必要がある。

図 5 は, レオロジー定数 $n$ の值が 2 であるH・B流体について, 図 2 の場合と同様な関係とし示したものである。同図に示される ように, 相対誤差を $1 \%$ 以内にするためには, 第 1 次近似では挟 角 $\alpha$ を 3 度以下にする必要がある。

図6は，レオロジー定数 $n$ の值が 10 である $\mathrm{H} ・ \mathrm{~B}$ 流体について 図 5 の場合と同様に示したものである。同図に示されるように, 挟角 $\alpha$ が 2 度以上では, 第 1 , 次近似では $1 \%$ 以内に抑えることが できないことが分かる。また，第 2 次近似を用いても挟角 $\alpha$ が 5 度の場合には相対誤差は $1 \%$ を超えることが分かる。

図7は， $\tau_{y} / K$ が 0.5 である場合， H・B 流体の $\phi_{1}$ および $\phi_{2}$ と $n$ との関係について，挟角をパラメータとして図示したものであ る。同図に示されるように，1\%以下に抑えるには第 1 次近似

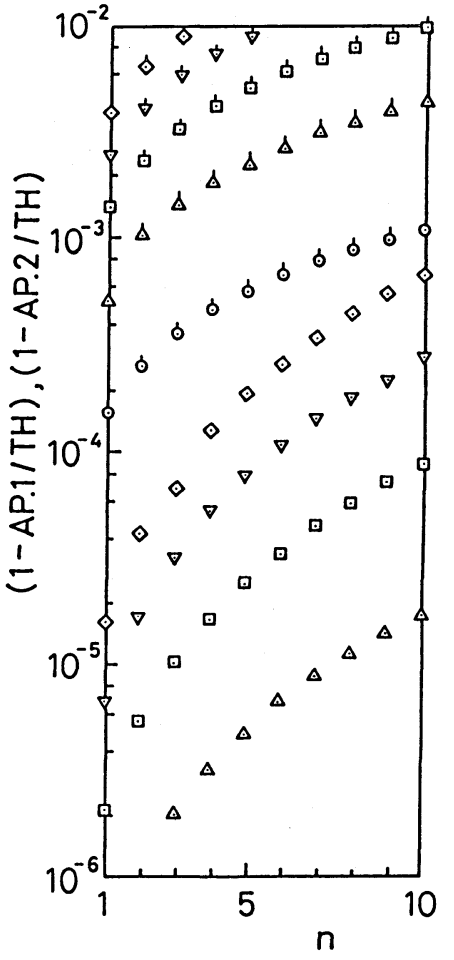

Fig. 3 Dependence of $\phi_{1}$ and $\phi_{2}$ on $n$ for various values of $\alpha$ for pseudo-plastic fluids.

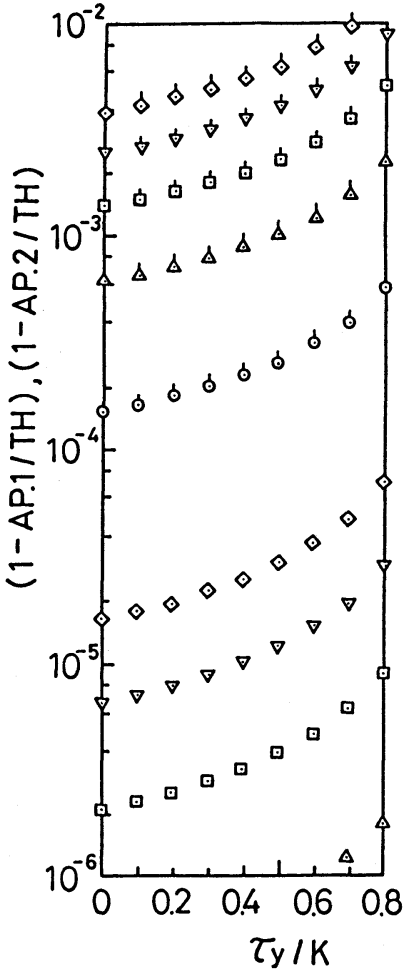

Fig. 4 Dependence of $\phi_{1}$ and $\phi_{2}$ on $\tau_{y} / K$ for various values of $\alpha$ for Bingham plastic fluids. 


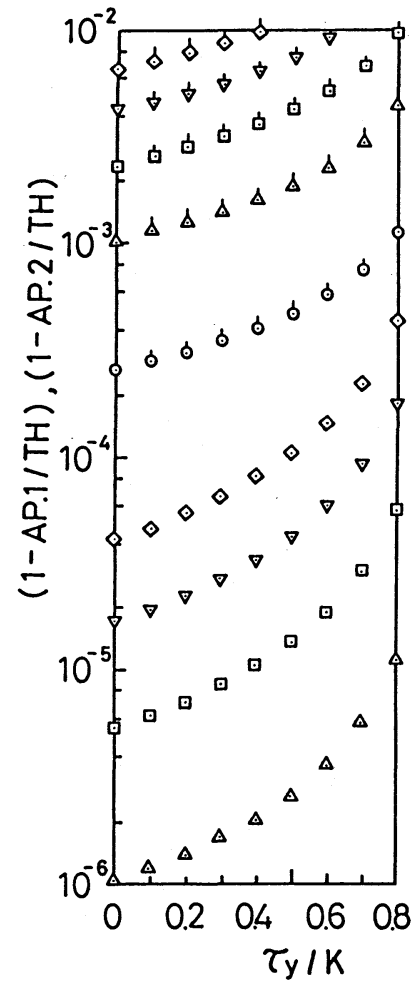

Fig. 5 Dependence of $\phi_{1}$ and $\phi_{2}$ on $\tau_{y} / K$ for Herschel-Bulkley model fluids. Sample calculation is made for $n=2$.

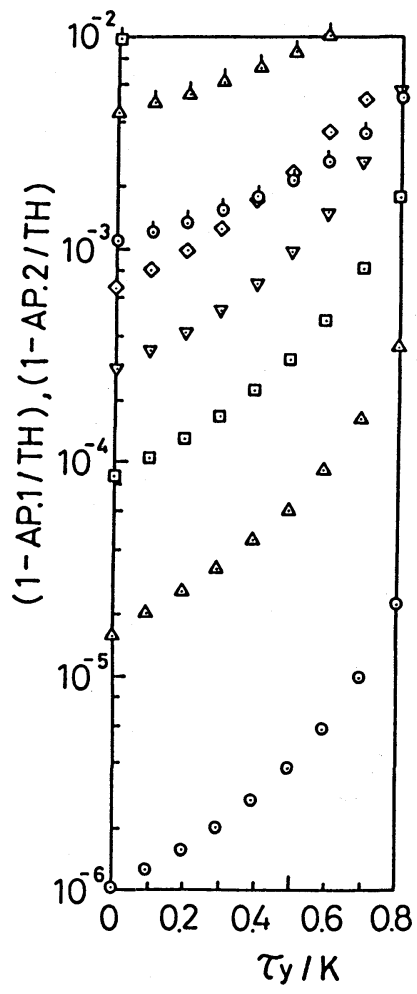

Fig. 6 Dependence of $\phi_{1}$ and $\phi_{2}$ on $\tau_{y} / K$ for Herschel-Bulkley model fluids. Sample calculation is made for $n=10$.

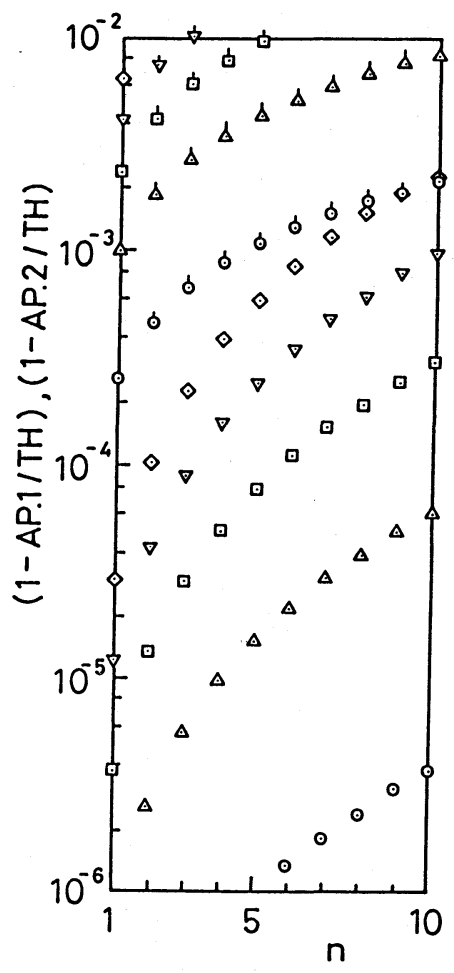

Fig. 7 Dependence of $\phi_{1}$ and $\phi_{2}$ on $\tau_{y} / K$ for Herschel-Bulkley model fluids. Sample calculation is made for $\tau_{y} / K=0.5$.

主な記号

$a:$ 円錐半径

$K$ : 定数

$M: ト ル ク$

$n$ : レオロジー定数

$P$ : 圧力

$V:$ 速度

$\alpha$ : 挟角

$\dot{r}:$ ずり速度

$\theta$ : 角度

$\mu$ : 粘度

$\tau$ : せん断応力

$\phi:$ 相対誤差

$\Psi=\pi / 2-\theta$

$\Omega, \omega$ : 角速度

添字

C : Casson

HB : Herschel-Bulkley

$y:$ 降伏

求めえた。さらに，H・B 流体の基礎式は，この流体モデルの特別 な場合として $\mathrm{P}$ 流体 $\left(\tau_{y}=0\right)$ ならびに $\mathrm{B}$ 流体 $(n=1)$ の基礎式 を包括している。

3. 第 1 次近似式を用いて流動解析をする場合，挟角 $\alpha$ が 2 度 以上の場合には誤差が 1 \%を超える場合があることが分かった。 また，第 2 次近似を用いれば，挟角 $\alpha$ が 4 度以下であれば，誤差 を 1 \%以内に抑えることができる。

終りに，本研究を遂行するにあたり，有益なご助言を頂きまし た東北大学教授故野田佳六先生に深く感謝申上げる。

なお，本研究の一部は文部省科学研究費によったことを付記し 謝意を表する。
参考文 献

1) 中川鶴太郎・神戸博太郎：レオロジー, 188〜189, (1967), みす ず書房，(東京)

2) Bogue, D. C. \&White, J.L.：レオロジーの理論と応用一非二= 一トン流体の工学的解析 (三石, 山中共訳) , 23〜24, (1972), 工業調查会 (東京)

3) 小野木重春 : 化学者のためのレオロジー, 31〜33, (1985), 化学 同人, (京都)

4) Oka, S. \& Takami , A. : Japan J. Appl. Phys.6, 258, (1967); 岡小天：レオロジーー生物レオロジーー，135，(1976)， 裳華房 (東京)

5) 森口ら：数学公式II, 138, (1979), 岩波書店 (東京) 